\title{
Introduction: Culture and Sustainable Communities
}

\author{
Nancy Duxbury \\ Centre for Social Studies (CES), University of Coimbra, Portugal
}

\author{
M. Sharon Jeannotte \\ Centre on Governance, University of Ottawa, Canada
}

During the second half of the 1980s, a vision of sustainable development with three dimensions (environmental balance, economic growth, and social inclusion) was developed, and enshrined in the Brundtland Report, Our Common Future (WCED 1987), and the Rio de Janeiro Earth Summit (1992). Both recent policy and research and the articles in this special issue assert that these dimensions alone do not reflect the complexity of society and the way people act in the world (UCLG, in this issue).

Over the past year, much of our research has focused on exploring the ways in which cultural considerations are incorporated into plans and processes to build 'sustainable cities' and communities, and the links between theory and practice at the local level (Duxbury \& Jeannotte 2010a, 2010b). We have found that both theory and practice are in exploratory stages providing a rich array of perspectives and insights on various dimensions of this relationship, but also challenging conceptual synthesis and strategic action. While this 'unsettledness' provides fertile ground for imagining and 'trail blazing' new pathways forward, it is also difficult, slow, and pioneering work.

We have also found that this is very much an international and multidisciplinary enterprise, with knowledge and ideas emerging through a variety of grassroots experiments, encompassing both academic writing and policy/planning documents, and fostered in community dialogues. Consequently, the articles in this issue are informed by a variety of disciplines as well as professional practice-based knowledge. And they encompass a wide geographic scope, providing insights and examples from Europe (Catalonia, Slovenia, Czech Republic, Bulgaria, and Germany), North America (Canada), South America (Brazil), Oceania (Australia), and Africa (South Africa).

To provide a brief context for the current issue, it is important to note that both research and practices concerning the inclusion of culture within sustainability are emergent and widely dispersed. Growing policy attention and thinking about culture and sustainable communities is evident in writing from Australia (Hawkes 2001, Dunphy 2005), New Zealand (NZMCH 2006), Europe (Pascual 2009, SALAR 2008, Thames Gateway North Kent 2006), and Canada

Dr. Nancy Duxbury is a Researcher at the Centre for Social Studies (Centro de Estudos Sociais - CES), University of Coimbra, Portugal. E-mail: duxbury@ces.uc.pt. M. Sharon Jeannotte is Senior Fellow at the Centre on Governance, University of Ottawa, Canada. E-mail: Sharon.Jeannotte@uottawa.ca.

Culture and Local Governance / Culture et gouvernance locale, vol. 3, no. 1-2, 2011. ISSN 1911-7469

(C) Centre on Governance, University of Ottawa, 55 Laurier Avenue East, Ottawa, Ontario, Canada K1N 6N5 
(Government of Canada 2005, Duxbury \& Gillette 2007, Jeannotte \& Andrew 2008, QMCCSW 2009); in research from Asia on sustainable cities and culture (Nadarajah \& Yamamoto 2007); in Brazilian writing exploring linkages between the cultural economy and sustainable development (Reis 2006); in European theorization on the arts and sustainability (Kagan \& Kirchberg 2008); in papers and reports from Africa (Edozien 2007, Oyawa 2008), the Caribbean (Nurse 2006), and the Pacific Islands (Hooper 2005; Synexe 2010) on the cultural essence of sustainable development; in recent conferences and panels on 'creative cities' and sustainability (two of which are reported in this issue); and in projects compiling 'greening' practices and policies of cultural organizations and agencies (Hartley 2009, Julie’s Bicycle reports; TippingPoint Australia 2010).

The theme is also found in international movements that are increasing the recognition of culture in public discourses, policy, and planning for sustainability, such as UNESCO's Decade for Education for Sustainable Development (2005-2014); Article 13 of the Convention on the Protection and Promotion of the Diversity of Cultural Expressions (UNESCO 2005, 2009); the United Nations General Assembly resolution on culture and development, which emphasizes the important contribution of culture for sustainable development (adopted 20 December 2010); Agenda 21 for Culture, promoted by United Cities and Local Governments since 2004; and the UCLG policy statement on 'Culture: Fourth Pillar of Sustainable Development' (approved 17 November 2010; in this issue).

The wide-spread shift to a sustainability paradigm for city planning makes this an important point in time to identify opportunities to integrate cultural considerations into broader sustainability policy and planning initiatives and to align cultural planning to community sustainability approaches and goals. In both cases, strengthening the connections between growing intercultural realities and sustainable community development is required. This special issue takes as a foundational understanding that culture is by nature diverse and evolving, and intercultural realities and relationships must be incorporated as integral to any understanding of culture and sustainability in contemporary cities and communities.

The articles in this issue take up these challenges. They reflect the current, exploratory phase of this area of research and practice, which features a rich array of alternate perspectives and understandings and is marked by pioneering efforts, on one hand, to conceptualize the relationships among culture, sustainability, and community development and, on the other hand, to operationalize and embed cultural considerations within local plans, policies, and processes. In the background of both areas, we find the growing need to rethink local governance processes and the ways our cities, our towns and, indeed, our societies are organized and encouraged to develop.

Several of the articles highlight some of the long-standing debates and concerns of cultural planning and policy, such as access, participation, diversity, and social cohesion, and develop arguments that support the integration of cultural elements and activities within broader community development and planning initiatives. Other articles suggest that grappling with these (and other) cultural issues within a context of sustainability offers a qualitatively different paradigm. Overall, we find that the varied perspectives in this issue, from both researchers and practitioners, tend to coalesce around concerns with two types of relationships: 'culture and sustainability' and 'culture and local governance'. 


\section{Culture and sustainability}

In our previous reviews of research literature and policy and planning documents, four main conceptual threads emerged to position culture within 'culture and sustainability' discourses related to local or urban development: (1) culture as capital; (2) culture as process and way of life, interacting with an environment; (3) culture as a central binding element providing the values underlying sustainable (or unsustainable) actions; and (4) culture as creative expression providing insights on environmental/sustainability concerns. All four dimensions can be observed within the articles in this special issue. However, a fifth approach to conceptualizing culture also emerges, one that emphasizes complexity, interdependence, networks, and emergence. This perspective is related to culture as 'process and way of life' but is much richer in its descriptive power through its concept of cultural relationships as interdependent networks that adapt in ever-changing ways (emergence) in relation to the complexities of the human environment or human ecology.

A variety of approaches are taken by the authors to the concept of culture as capital. Kagan \& Hahn suggest that creative cities may breed unsustainability if the focus is too heavily on physical and economic capital and if planners are not sensitive to 'the creativity and open interdependence of webs of life'. O'Shea also discusses how embodied or objectified notions of cultural capital must be embedded within a social context and cannot be separated from that context. She goes so far as to say that without a social world of interaction, cultural capital has no meaning. Clark \& Gilmour take another approach by examining how an intercultural arts partnership program can build the individual cultural capital of youth participants, thereby contributing to community social sustainability. Savova and Yue, Khan \& Brook also link community cultural participation to the accumulation of social capital.

Culture as a process and a way of life is considered from several angles in the articles, frequently intertwined with the notion of cultural citizenship. Yue, Khan \& Brook define cultural citizenship as the set of capacities that provide the necessary support for civic participation and the activation of citizen rights, and suggest that this concept may be a useful way to consider the intersection between community engagement in cultural activities and strategies of community capacity-building. They also make the point that community development can only be sustainable if members of a diverse resident population are able to come together to experience each other's cultures in a variety of ways and settings. Goldbard also takes up the idea of cultural citizenship, observing that collective art-making is a powerful means of cultivating meaningful belonging, participation, and mutual responsibility.

Savova examines how community cultural planning, when based on an integrated system of social relations and cultural codes, can serve as an anchor for a network of community cultural centres that promote individual creative potential and cultural citizenship among formerly marginalized individuals. From his perspective as a museum professional, Worts discusses how culture, as both a product and a process of relationships, is key to the adaptive renewal that will be required to ensure sustainability - both in the natural world and in human societies.

Culture as a vehicle for sustainable values is also examined by Worts, who looks at how processes of human adaptation to a changing world, grounded within the context of personal and collective values, can be fostered by local cultural organizations such as museums. Kagan \& Hahn explore the notion of unsustainability, suggesting that the values and characteristics of modernity 
that privilege short-term yields and short-term satisfactions can lead to a 'corrosion of neighbourhoods' and a loss of identification with the city or community. Related to this, several authors also discuss culture as creative expression that can provide insights on environmental and sustainability concerns. Kagan \& Hahn examine how the arts offer a social arena for multiple forms of reflexivity and community empowerment, describing the role of artists in Hamburg in resisting the gentrification of an historic neighbourhood. O'Shea provides examples of two arts-based community projects (Otesha and Vancouver's Urban Binning Units photovoice project) that help build social capital, empower individuals to undertake projects for a sustainable future, and contribute to a style of governance that is inclusive, participatory, equitable, and sustainable.

A conceptual element in these articles that we have not seen treated extensively in other 'culture and sustainability' literature is that of complexity and interdependence. Kagan \& Hahn, Savova, and Worts examine this concept from various angles to illustrate how it ties culture to sustainability. Kagan \& Hahn suggest that a new literacy of sustainability be attentive to complexity and to non-linear logics grounded in diversity and in cross-pollination between different social networks and urban contexts. Savova emphasizes that grassroots networks are critical to the sustainability of a community, noting that cultural planning must be sensitive not only to interconnections among network nodes, but must also take into account lapse of time (longer-term vision), looseness (responsive to the local environment), and locality (context). Worts looks at culture as an adaptive process, rather than a product or a class of products, and examines culture's role in the adaptive renewal of human societies - a role that he considers to be grounded in relationships and complex feedback loops and linkages.

\section{Culture and local governance}

Governments and organizations in various places internationally have been attempting to bridge the gap between theories and practice in relation to 'culture and sustainability' through bringing together two processes: cultural planning and transition management. Cultural planning has been described as an inclusive, multi-stakeholder consultation and decision-making process to think strategically about how collective actions can encourage cultural vibrancy, and how culture can contribute to civic goals and be integrated into a wide range of municipal actions (Russo \& Butler 2007). Transition management is a technique that 'combines an orientation toward a long-term vision of "sustainable development" with short-term experimental learning to probe options and find pathways to realise the vision' (Vo $\beta$ et al. 2009: 277), an approach that underlines planning for sustainable development.

The marriage of these two processes is a response to what Newig et al. (2007) have called 'the limits to rational steering' in governance for sustainable development (p. 185). These limits recognize that goals within each dimension of sustainability are contested; that knowledge of the complex dynamics among society, technology, and nature is limited; and that power to shape change is distributed across a multitude of actors and systems (Newig et al. 2007).

Several of the articles in this special issue explore this approach. Some focus on what is privileged or highlighted - the partnerships that are central to successful outcomes and the need to respect the integrity of the systems that sustain the community. Others explore the barriers that exist to successful integration of culture within sustainability planning. How can local authorities meet 
obligations imposed from above without compromising the integrity of the local cultural ecosystem? How are 'top-down' and 'bottom-up' processes strategically 'converged'? Governance issues are at the heart of many disputes and disjunctures, particularly with regard to the needs of the dispossessed and marginalized. Several of the articles describe various local area initiatives that attempt to operationalize linkages between culture and sustainability, working from both 'topdown' and 'bottom-up' and also by incorporating 'horizontal' approaches within municipal government structures.

In terms of efforts driven from above, Hajek, Novosak \& Bednar examine the efforts of two municipalities to implement Local Agenda 21 in the Czech Republic, and seek to understand why one municipality incorporated culture into its overarching Agenda 21 framework while another did not. They conclude that the incorporation of culture in these initiatives was highly related to the direct involvement (or not) of cultural actors in Local Agenda 21 activities.

Martinez \& Rius describe the planning framework of the Government of Catalonia (an example of territorial planning) that seeks to establish equitable access to cultural infrastructure by mapping local needs and deficits and meshing this overall framework with the cultural needs and priorities of local communities and governments. The authors also examine how this classic planning process is being aligned with environmental concerns (e.g., retrofitting for eco-efficiency, minimization of travel requirements).

While Martinez \& Rius give a fairly encouraging account of the relationship between culture and sustainability as reflected in the cultural facilities plan of the Government of Catalonia, Ursic comes to some less positive conclusions about the formal spatial planning system in Ljubljana, Slovenia. In his view, in many cases urban planning fails to take into account increasing cultural diversity and the social tensions arising from it - a concrete illustration of the need to link planning techniques and processes to 'soft' socio-cultural values and dynamics in order to plan for and practice culturally informed community sustainability.

Two of the case studies in this issue examine more 'bottom-up' or 'horizontal' approaches to cultural planning and community sustainability. Stanborough describes efforts in the city of Kelowna in British Columbia, Canada, to integrate culture into the Official Community Plan based on both community consultations and City Council leadership. She characterizes the exercise as a 'small success story' and is cautiously optimistic about the possibility of integrating the fourth pillar of cultural vitality into overall community sustainability plans and city-wide municipal policy. On the other side of the world, Yue, Khan \& Brook examine how the City of Whittlesea in Australia has attempted to integrate cultural planning with other planning streams and to prioritize cultural policy objectives within this context. As previously noted, notions of culture and sustainability are being framed in terms of social equity, social cohesion, social inclusion, and social capital. While these considerations are embedded within the city's official planning documents, Yue and her colleagues note the challenges involved in translating them into an adequate framework for local cultural indicators.

\section{Towards more culturally vibrant and sustainable communities}

In many ways, this special issue reflects the current cultural zeitgeist, a moment in time when there seems to be a general desire (prominent among the articles in this issue) for rebalancing. In this 
rebalanced environment, 'professional arts' would provide room for 'community arts' and community engagement, and quantitative indicators measuring short-term outcomes would be deemphasized a bit to give room for 'qualitative approaches' and recognize intangible outcomes and long-run impacts. In this rebalanced world, urban development would be more sensitive to residents and socio-cultural realities and less eager to embark upon big-money redevelopments to attract an 'outside' mobile creative class. These themes heavily influence thinking about a more sustainable basis of policy and collective action going forward.

This process of rebalancing acknowledges the real contributions of artists and other creative professionals and organizations in advancing operational 'greening' innovations in multiple cultural disciplines and fields; the multifaceted contributions of cultural industries, institutions, and activities to the economic well-being of cities and communities; and the aesthetic inspirations, responses, and artistic campaigns that inform our knowledge and perceptions of the world and our way of living in it (as highlighted by Kagan \& Hahn, Clark \& Gilmour, and O'Shea among others). However, alongside these elements, the articles in this issue tend to focus on culture as an important component of interdependent processes of human adaptation in a changing world, and collectively argue that the process of building sustainable communities is fundamentally a socio-cultural issue. Appreciation and positive engagement with cultural diversity (expressed as cultural heterogeneity, diversity, multicultural and intercultural interactions and exchange, cultural empowerment, inclusivity, equity, and giving voice to all groups in a population); openness of mind and territories; and the importance of participation and dialogue in building social capital and social cohesion, creativity, well-being, and resilience are recurring themes.

Cities and communities are socially and culturally constructed places, embodied and reflected in their physical forms and spaces, the patterns of life that play out within them, and the innovations and forms of creativity that are enabled by these environments. Within their visions of more sustainable communities, the authors emphasize genuinely participatory, 'bottom-up' projects, activities, and processes that are fostered as iterative contributions towards long-term development. Intersectoral (e.g., ecological-social-cultural), small-scale, and geo-culturally sensitive urban development and engagement are recommended. Artistic processes play important roles in societal transition to a more sustainable basis: they can create new spaces for dialogue; enable new ways of thinking, communicating, and building competencies that link cognitive and experiential insights; and catalyze shifts of societal consciousness, increasing both awareness and knowledge collectively contributing to the transformation of individuals and communities over time.

Physical places in which these processes can be fostered also figure prominently. Conceptually, the authors describe 'creative space' in which one can discover and develop one's creative potential and capacities for cultural citizenship; spaces where people 'open themselves up to the emergence of new insights' (Worts); spaces that promote regular social exchange through inclusive art activities. The emphasis is on geographically distributing such cultural centres and amenities around cities, decentralizing in order to take better advantage of the cultural diversity of different neighbourhoods and also to be 'close to home' to decrease car dependency and travel time to the venues. Cultural facilities are viewed as fundamental factors for communities in promoting their culture, creativity, cohesion, and sustainability; and as a means of conveying and embodying values of environmental sustainability in their physical design, operation, and management. 
From a governance perspective, the authors view strategies for urban sustainability planning and cultural planning as complementary and both conceptually and pragmatically important. Ongoing incorporation of cultural components in city form and development requires recognizing culture as an important part of holistic community building, and integrating cultural considerations into all processes of planning and development (Mercer 2002). This requires solidifying culture's place in municipal planning in multiple ways, such as adopting culture as a pillar of sustainable development within sustainability checklists and assessments; integrating cultural considerations within all municipal departments through policy and inter-departmental collaboration; and bringing cultural considerations into decision-making about city planning, investments, land use, and development. From a cultural planning perspective, increased emphasis is placed on community cultural development and wide-spread participation, supported by regular, long-term social interactions and by basic institutional support for distributed community cultural centres.

Partnerships, cooperation, and appreciation of the 'surrounding terrain' (Stanborough) also play important roles in helping planners to fully understand culture's place in the geographical/ environmental and socio-economic landscape. Intergovernmental cooperation through complementary regional and local planning frameworks forms part of this environment, working together to address historical imbalances, ensure equitable distribution of services, and establish technical and environmental baseline standards, while avoiding the logic of standardization and allowing local communities to identify action priorities through genuine participation and dialogue with citizens.

From an operational perspective, the authors envision open, adaptive, participatory, and creative governance models that offer transparent forms of genuine, effective participation, dialogue, and mutual learning, and respond to a diversity of voices and alternative modes of communication. Within this inclusive, adaptive, and exploratory model, arts-based approaches to information-gathering, engagement with the citizenry, and assessment play important roles. On the subject of assessment, the authors recognize the challenge of developing appropriate indicators that can capture both tangible aspects of environmental sustainability (e.g., for cultural facilities) and intangible outcomes of community arts participation (such as emotional, psychological, and social transformations). Such indicator systems are needed to measure the effectiveness of local policies, programs, and other initiatives in integrating cultural and sustainability goals and, more broadly, to monitor systems by providing feedback loops that incorporate diverse voices and perspectives. Changes along these lines could have an important impact on subsequent policy development based on this expanded base of knowledge and voices.

The transition to more holistically sustainable, inclusive, and resilient cities and communities is a fundamental social challenge requiring multiple perspectives and ideas. As Goldbard observes in the book excerpt included at the end of this issue, we need to look at our communities with a wide lens and an uncolonized mind, by which she means with a perspective that sees what is actually there and not necessarily what the experts tell us is there or should be there. Guiding this transition and the (re)organization of our ways of living together requires new ways of thinking, discussing, and acting at individual and collective levels. The integration of culture within sustainable communities must seek out a more balanced array of insights and knowledge from local citizens, practices in different parts of the world, multiple academic disciplines, and a variety of front-line 
practitioners - the artists, curators, cultural administrators, and planners who develop and implement policies, practices, and programmes to foster liveable and vibrant communities.

This special issue is one contribution towards this challenge. The diverse nature of the articles in the collection highlights the value of a 'wide lens' in understanding how culture and sustainability fit together in a variety of settings. Above all, the articles in this issue indicate how necessary it is to start from what is actually there, on the ground, in the community, and to listen attentively and respectfully to the opinions of everyone who lives and works there. Whether one accepts culture as a fourth pillar of sustainability or as an overarching framework - a process and way of life within a complex web of interdependent networks - one cannot ignore the need to factor culture into the sustainability equation at the local level. We hope that this special issue of Culture and Local Governance provides food for thought and, perhaps, guidance for the many communities throughout the world who are currently grappling with the challenge of integrating culture into community sustainability planning.

\section{References}

Agenda 21 for culture. (2004). Developed by United Cities and Local Governments Working Group on Culture. www.agenda21culture.net

Dunphy, K. (Ed.). (2005). The fourth pillar of sustainability - Conference report. Melbourne: Cultural Development Network. Conference held at Melbourne Town Hall, 29-30 November 2004. http://culturaldevelopment.net.au/downloads/FPS_ConferenceRpt.pdf

Duxbury, N. \& Gillette, E. (2007, February). Culture as a key dimension of sustainability: Exploring concepts, themes, and models. Working paper no. 1. Vancouver: Centre of Expertise on Culture and Communities, Creative City Network of Canada/Simon Fraser University. www.cultureandcommunities.ca/downloads/WP1-Culture-Sustainability.pdf

Duxbury, N. \& Jeannotte, M.S. (2010a, September). Culture, sustainability and communities: Exploring the myths. Working paper no. 353, Oficina do CES. Originally presented at the $6^{\text {th }}$ International Conference on Cultural Policy Research, Jyväskylä, Finland, 25 August 2010. www.ces.uc.pt/ publicacoes/oficina/index.php?id=2982

Duxbury, N. \& Jeannotte, M.S. (2010b). From the bottom-up: Culture in community sustainability planning. Paper presented at the 3rd ESA Sociology of Culture Research Network Mid-term Conference, 'Culture and the Making of Worlds', Università Bocconi, Milan, Italy, 7-9 October 2010.

Edozien, N.N. (2007). Cultural divergence and education towards sustainable development - an African viewpoint. Kulturelle Vielfalt, No 2 (in BNE-Journal, 2009).

Government of Canada. (2005). Integrated community sustainability planning - a background paper. Discussion paper for 'Planning for Sustainable Canadian Communities Roundtable', organized by the Prime Minister's External Advisory on Cities and Communities, 21-23 September 2005.

Hartley, J. (2009, January). Arts and ecological sustainability. D’Art Topics in Arts Policy, no. 34. Sydney: International Federation of Arts Councils and Culture Agencies. www.ifacca.org/topic/ecologicalsustainability [21 December 2010]

Hawkes, J. (2001). The fourth pillar of sustainability: Culture's essential role in public planning. Commissioned by the Cultural Development Network, Victoria. Melbourne: Common Ground Publishing. http://culturaldevelopment.net.au/downloads/FourthPillarcomplete.pdf [21 December 2010] 
Hooper, A. (Ed.). (2005). Culture and sustainable development in the Pacific. Canberra: ANU ePress \& Asia Pacific Press.

Jeannotte, M.S. \& Andrew, C. (2008). Operational guidelines for incorporating culture into sustainable development policies: A Canadian perspective. Report prepared for Department of Canadian Heritage.

Julie's Bicycle - publications. www.juliesbicycle.com

Kagan, S. \& Kirchberg, V. (Eds.). (2008). Sustainability: A new frontier for the arts and culture. Frankfurt: Verlag für Akademische Schriften.

Mercer, C. (2002). Towards cultural citizenship: Tools for cultural policy and development. Stockholm: The Bank of Sweden Tercentenary Foundation \& Gidlunds Forlag.

Nadarajah, M. \& Yamamoto, A.T. (Eds.). (2007). Urban crisis: Culture and the sustainability of cities. Tokyo: United Nations University Press.

Newig, J., Voß, J.-P. \& Monstadt, J. (2007). Editorial: Governance for sustainable development in the fact of ambivalence, uncertainty and distributed power: An introduction. Journal of Environmental Policy \& Planning, 9(3): 185-192.

New Zealand Ministry for Culture and Heritage (NZMCH). (2006). Cultural well-being and local government. Report 1: Definition and context of cultural well-being. Wellington, NZ: New Zealand Ministry for Culture and Heritage.

Nurse, K. (2006, June). Culture as the fourth pillar of sustainable development. Paper prepared for Commonwealth Secretariat, London, UK.

Oyawa, W.O. (2008). Local technologies and spirituality as the anchor for sustainable development. In R.A. Lopez (Ed.), Progress in sustainable development research (pp. 251-262). New York: Nova Science Publishers.

Pascual, J. (2009). Culture and sustainable development: Examples of institutional innovation and proposal of a new cultural policy profile. Barcelona: UCLG Culture Committee.

Reis, A.C.F. (2006). Economia da cultura e desenvolvimento sustentavel. Brazil: Manole.

Russo, A. \& Butler, D. (2007). Cultural planning toolkit. Vancouver: Creative City Network of Canada.

SALAR (Swedish Association of Local Authorities and Regions). (2008). Culture in the sustainable society. Stockholm: SALAR.

QMCCSW (Quebec Ministry of Culture, Communications and the Status of Women). (2009). Notre culture, au coeur du développement durable : plan d'action de développement durable 2009-2013. Quebec: QMCCSW.

Synexe Consulting Limited. (2010). Valuing culture in Oceania: Methodology and indicators for valuing culture, including traditional knowledge, in Oceania. Report prepared for the Human Development Programme of the Secretariat of the Pacific Community. Noumea, New Caledonia: Secretariat of the Pacific Community.

Thames Gateway North Kent. (2006). Sustainable culture, sustainable communities: The cultural framework and toolkit for Thames Gateway North Kent.

Wynne-Jones, A. \& Settle, D. (eds.). (2010, October). Greening the arts: Thinkpieces for a zero carbon future and a survey of sustainable arts practices. Melbourne/Sydney: TippingPoint Australia. http://tippingpointaustralia.com/static/files/assets/dd35ab7a/Greening_the_Arts.pdf [7 January 2011]

UNESCO. (2005). Convention on the Protection and Promotion of the Diversity of Cultural Expressions.

UNESCO. (2009, June). Article 13 of the Convention on the Protection and Promotion of the Diversity of Cultural Expressions. Operational guidelines - Integration of culture in sustainable development. Approved by the Conference of Parties at its second session (June 2009).

United Nations - General Assembly. (2010). Culture and development. Resolution adopted 20 December 2010. http://portal.unesco.org/culture/en/ev.php-URL_ID=41466\&URL_DO=DO_TOPIC\&URL_ SECTION=201.html [3 January 2011] 
Voß, J.P., Smith, A. \& Grin, J. (2009). Designing long-term policy: Rethinking transition management. Policy Sciences, 42: 275-302.

WCED (World Commission on Environment and Development [Brundtland Commission]). (1987). Our common future. United Nations. www.un-documents.net/wced-ocf.htm 